Kenward, B and Osth, T

Five-Year-Olds Punish Antisocial Adults

Kenward, B and Osth, T (2015) Five-Year-Olds Punish Antisocial Adults. Aggressive Behaviour, 41 (5). pp. $413-420$.

doi: 10.1002/ab.21568

This version is available: https://radar.brookes.ac.uk/radar/items/5b152447-a595-4a81-b5f5-b7f4c730baec/1/

Available on RADAR: August 2016

Copyright (C) and Moral Rights are retained by the author(s) and/ or other copyright owners. A copy can be downloaded for personal non-commercial research or study, without prior permission or charge. This item cannot be reproduced or quoted extensively from without first obtaining permission in writing from the copyright holder(s). The content must not be changed in any way or sold commercially in any format or medium without the formal permission of the copyright holders.

This document is the postprint version of the journal article. Some differences between the published version and this version may remain and you are advised to consult the published version if you wish to cite from it. 


\title{
Five-year-olds punish antisocial adults
}

\author{
Ben Kenward and Therese Östh \\ Department of Psychology, Uppsala University
}

Correspondence to: Ben Kenward, Institutionen för psykologi, Box 1225, 75142 Uppsala, Sweden. E-mail: ben.kenward@wolfson.oxon.org. Phone:+46 768500221.

10

Accepted for publication in Aggressive Behavior 21/09/2014

\begin{abstract}
The human tendency to impose costs on those who have behaved antisocially towards third parties (third-party punishment) has a formative influence on societies, yet very few studies of the development of this tendency exist. In most studies where young children have punished, participants have imposed costs on puppets, leaving open the question as to whether young children punish in real third-party situations. Here, five-year-olds were given the opportunity to allocate desirable or unpleasant items to antisocial and neutral adults, who were presented as real and shown on video. Neutral individuals were almost always allocated only desirable items. Antisocial individuals were instead usually allocated unpleasant items, as long as participants were told they would give anonymously. Most participants who were instead told they would give in person did not allocate unpleasant items, although a minority did so. This indicates that the children interpreted the situation as real, and that whereas they genuinely desired to punish antisocial adults, they did not usually dare do so in person. Boys punished more frequently than girls. The willingness of preschoolers to spontaneously engage in third-party punishment, occasionally even risking the social costs of antagonizing an antisocial adult, demonstrates a deep-seated early-developing punitive sentiment in humans.
\end{abstract}

Keywords: Third-party punishment; preschoolers; children; antisocial behavior 


\section{Five-year-olds punish antisocial adults}

Third-party punishment is behavior intended to cause a negative outcome to an individual who violated a conventional or moral norm, even though the punisher was not directly affected by the violation (Jensen, 2010). Third-party punishment is extremely widespread in adult humans (Henrich et al., 2006; Mathew \& Boyd, 2011). It is argued that higher costs for antisocial behavior promote cooperation, and thereby enable the large-scale cooperative networks which characterize human societies (Boyd \& Richerson, 1992; Fehr \& Fischbacher, 2003; Fehr \& Gächter, 2002; Gintis, Henrich, Bowles, Boyd, \& Fehr, 2008; Lergetporer, Angerer, Glätzle-Rützler, \& Sutter, 2014; Nowak \& Sigmund, 2005). Thirdparty punishment contrasts with second-party punishment (direct retaliation) in several ways. Because the costs of third-party punishment are mainly confined to the punisher, but the benefits are spread across the group, it is more complex (though not impossible) to explain in functional evolutionary terms (Jensen, 2010; Nowak \& Sigmund, 2005). The psychological processes underlying third-party punishment are also more complex: unlike second-party punishment, it cannot be explained by a tendency to directly reciprocate antisocial behavior, but rather requires a response to a norm violation which was not directly experienced, but observed vicariously. These differences may explain why third-party punishment, unlikesecond party punishment, has not been clearly demonstrated in non-human species (Melis \& Semmann, 2010; Raihani, Thornton, \& Bshary, 2012; Riedl, Jensen, Call, \& Tomasello, 2012).

It has been suggested on the basis of experiments (Henrich et al., 2006; Price, Cosmides, \& Tooby, 2002), ethnological observation (Mathew \& Boyd, 2011), and evolutionary models (Boyd \& Richerson, 1992; Nowak \& Sigmund, 2005) that punitive sentiment may be an inherited domain-specific mechanism that evolved because individuals benefit from the cooperation that it enables (Gintis et al., 2008; Robinson, Kurzban, \& Jones, 2007). Related to this is the finding that participants in experimental studies of attitudes toward punishment give justifications for punishment that are incompatible with their true motivations. Deterrence is frequently proposed as a justification for punishment, even though the majority are in fact motivated by a retributive sentiment that norm violations deserve punishment (Aquino, Tripp, \& Bies, 2001; Carlsmith \& Darley, 2008; Keller, Oswald, Stucki, \& Gollwitzer, 2010). According to the evolutionary view, deterrence may be advocated because this is how subjects rationalize their motives, whereas retribution is the true underlying motive produced by the evolved system. At least in second-party punishment contexts, punishers experience greater reward-circuit activation in the brain when they punish or observe the punishment of norm-violators (de Quervain et al., 2004; Singer et al., 2006).

Following from this, the social impact of third-party punishment may not be entirely positive. Possibly because official justifications for institutionalized punishment are apparently cold and rational, but personal motives are in fact often affect-laden and retributive, the motive to punish has created criminal justice systems which have been argued to be cruel and inefficient (Drucker, 2011; Garland, 2001; Rubin, 2004; The Economist,

70 2010). For example, $1 \%$ of the adult population of the USA is in prison (Pew Center, 2008) even though it is highly debatable whether this reduces crime rates (Cullen, Jonson, \& Nagin, 2011).

Given the great impact on human societies of third-party punitive sentiment, and given the suggestion of an evolved domain-specific mechanism, it is important to understand the ontogeny of the human desire to enact third-party punishment. Despite this, there is only one study in which preschoolers have been given the opportunity to actively engage in third-party punishment of real norm-violators. A resource-exchange paradigm was 
used in which children could pay sweets to deprive sweets from an individual who had shared in a selfish manner (Jordan, McAuliffe, \& Warneken, 2014). Although six- and eight-yearolds punished (with punishment levels depending on in-group or out-group status of the punisher and third-party), a pilot study indicated that five-year-olds did not. One goal of the current study is therefore to use a simpler method, involving harm to person and property rather than an economic paradigm, with the hypothesis that third party punishment will also be observed in younger children in a simpler context.

Other studies do demonstrate that younger pre-schoolers disapprove of and discriminate against norm-violators, for example by avoiding helping them (Dahl, Schuck, \& Campos, in press; Kenward \& Dahl, 2011; Vaish, Carpenter, \& Tomasello, 2010; Vaish, Missana, \& Tomasello, 2011). Such passive avoidance behavior may be intended to cause harm to norm-violators. Alternatively, it may arise from other mechanisms such as reduced

90 motivation to interact with antisocial individuals, and therefore does not comprise conclusive evidence for punishment. Data directly concerning younger pre-schoolers' attitudes to active punishment so far comes only from interview studies (Smetana, 1981, 2006; Smetana, Schlagman, \& Adams, 1993; Stern \& Peterson, 1999; Tisak \& Turiel, 1988) and studies involving punishment of puppets or dolls (Hamlin, Wynn, Bloom, \& Mahajan, 2011; 95 Kenward \& Östh, 2012; see also Vaish et al., 2011).

Interview studies indicate that from at least three years, children frequently answer yes when asked if norm-violators should "get into trouble". Children in these studies take into account the seriousness of the violation and the intention behind the action, demonstrating a reasonably mature understanding of the appropriateness of punishment.

100 However, given the often-wide gap in studies of moral psychology between endorsement of hypothetical behavior and behavior which respondents will themselves perform (FeldmanHall et al., 2012; also in young children Smith, Blake, \& Harris, 2013), it is not clear that this implies that young children are motivated to engage in third-party punishment. Although Smetana et al. (1993) asked children about real transgressions they had observed, 105 as in other interview studies they could only hypothetically advocate punishment.

Two published studies (Hamlin et al., 2011; Kenward \& Östh, 2012; though see also Riedl, Jensen, Call, \& Tomasello, 2011) indicate that preschoolers are willing to engage in third-party punishment of norm-violating puppets or dolls. Kenward and Östh (2012) asked four-year-olds to freely re-tell doll stories first told by adult demonstrators in

110 which either the perpetrator or the victim of an unprovoked attack had been punished by a parent doll. When the victim had been punished, the participants usually changed the story so that the perpetrator was instead punished. The authors concluded that four-year-olds believed that punishment was appropriate for norm violators, and were willing to enact it themselves.

Hamlin et al. (2011) asked children in their second year (mean age 20 months)

115 to give a treat to a puppet. The only source of treats were two other puppets, one of whom had previous behaved antisocially and one of whom had behaved prosocially, and the participants were instructed to choose which puppet to take a treat from. They tended to take a treat from the antisocial puppet.

Although these two studies indicate that some form of punitive sentiment is

120 likely to be developing early, they have a serious limitation. From the middle of the second year children begin to understand pretense (Walker-Andrews \& Kahana-Kalman, 1999), which means that children punishing puppets may understand that they are not really punishing. This is important not least because one of the most interesting properties of thirdparty punishment in adults and older children is that they are often willing to pay a cost in order to enact punishment even though they receive no direct benefit (de Quervain et al., 
2004; Fehr \& Gächter, 2002; Henrich et al., 2006; Jordan et al., 2014; Lergetporer et al., 2014). In experimental studies, such costs are usually economic, but in real life, the costs to punishers are frequently social and consist of a risk of antagonism from the punished individual (Janssen \& Bushman, 2008). As children may appreciate that there is little risk of

130 antagonism from puppets (they are used in such studies precisely because children are comparatively uninhibited towards them) such studies cannot demonstrate that children are motivated to engage in real and potentially costly third-party punishment. The primary goal of the current study is therefore to investigate whether young children will use physical harm to punish an individual whom they believe is real and who was antisocial to a third party.

A further limitation of the above puppet studies is that participants were forced or encouraged to assign a negative outcome to an individual. While the studies clearly show that young children prefer to inflict a negative outcome on an antisocial puppet than on a neutral one, they do not clearly indicate that young children would spontaneously allocate a negative outcome to an antisocial individual if not encouraged or forced to allocate it to

140 someone. The current study therefore includes the option of not assigning a negative outcome to anybody.

The design consists of allowing participants to choose negative or positive outcomes for an antisocial and a neutral adult. The antisocial actions were displayed on video, but were presented as recordings of something which had really been performed by

145 real people. Using two between-subjects conditions, we manipulated whether or not the participants believed they would assign the outcomes in person or while anonymous to the recipients. We predicted that participants would be less likely to allocate a negative outcome to the antisocial recipient in person, because of the potential cost of antagonizing an antisocial adult. This manipulation was included as an investigation of the participants'

150 ability to appreciate the potential cost of enacting punishment, and secondarily as a test of the validity of our method. If participants did not experience their punishment allocations as real, they would not be predicted to be more willing to punish when unknown to the punishment recipient.

Disgusting-tasting fake sweets (of the sort available in joke shops) were used 155 as the negative outcome which participants could allocate. Normal good-tasting sweets were also available for allocation. Disgusting fake sweets were used because they were judged to be a good way to give young children the impression they could inflict a real punishment at a distance - the experimenter portrays the experience of eating these sweets as highly unpleasant. Action likely to cause someone to ingest these sweets therefore qualifies as

160 aggressive according to a standard definition: "behavior directed toward the goal of harming or injuring another living being who is motivated to avoid such treatment" (Baron \& Richardson, 1994, p.7). Because boys are typically found to be more aggressive than girls (Card, Stucky, Sawalani, \& Little, 2008), we examine gender differences in disgusting sweet allocation. Five-year-olds were tested as this was the youngest age at which we were

165 confident that children would fully understand the implications of anonymous and in-person giving, and the implications of giving something apparently nice but actually disgusting tasting.

\section{Method}

\section{Participants}

Participants were a self-selected sample who responded to an invitation letter sent to all families with children of appropriate age living in Uppsala, a medium-size Swedish city; therefore, participants were mostly ethnically Swedish and had mixed socioeconomic 
backgrounds. Forty-eight 5-year-olds $(M=5 ; 2, \min =4 ; 11, \max =5 ; 3,24$ girls $)$ were divided randomly between the anonymous and in-person conditions. No participants were excluded from analysis. According to Swedish law and in compliance with APA ethical standards the Uppsala Regional ethical committee approved the study design.

\section{Materials and stimuli}

Throughout the experiment two actors were displayed on either side of a computer screen placed on a table at which the participant sat. Which actor was neutral and

180 which was antisocial was counterbalanced. There was a real box for receiving presents for each actor, which matched her shirt color (black and white). One red packet of disgusting fake sweets and two green packets of good-tasting sweets were available for distribution.

\section{Procedure}

The experiment was divided into four phases: sweet familiarization, third-

185 party interaction, sweet distribution, and distribution justification. Only the sweet distribution phase differed between conditions. One experimenter carried out the procedure. During sweet familiarization, she explained that she had two types of sweets, one normal and one fake and disgusting, but that she had forgotten which was which and would therefore have to taste them to find out. First tasting a sweet from a green packet, she said that they were real tasty

190 sweets. Then tasting a sweet from the red packet, she acted as if she was eating something extremely disgusting, and explained that it tasted horrible like worms. As an aid to the participants' memory, she asked them to place a sticker with a picture of real sweets on each green packet, and a sticker showing worms on the red packet.

Introducing the third-party interaction phase, she pointed to the actors on the screen, who until this point had been still, and said "This is Anne and this is Caroline. This is something that really happened one day." The view switched to a man seen from behind drawing two pictures, while a voice-over stated "This is Sam. One day Sam was going to visit Anne and Caroline. He made a drawing for each of them". The view switched back to Anne and Caroline, and in counterbalanced order, Sam was seen to give each of the actors a

200 drawing by placing it in a box on their table. The neutral actor received the drawing with a neutral demeanor, saying "Oh, a picture. I think it's a house. I'll put it here", and placed it on the table. The antisocial actor received the drawing with an aggressive demeanor, saying "What a bad drawing. It's really ugly. I'm tearing it up", and did so. During the third-party interactions, the experimenter sat so she could not see the screen, and wore headphones, to

205 ensure she was blind to which actor was antisocial. After giving each drawing Sam retreated out of view, but note that even 18-month-olds evidence understanding of the consequences of antisocial actions without seeing the victim's reaction (Vaish, Carpenter, \& Tomasello, 2009).

The distribution phase began immediately after. Remaining so she could not

210 see the screen, the experimenter placed a present box in front of each actor, explaining that they would each be given the box with something inside. In the anonymous condition, the experimenter said "You can decide what they get, but they don't know who we are. The boxes will be sent by post, and the letter carrier will give them to Anne and Caroline. So they won't know it's us who sent the boxes." In the in-person condition, the experimenter said

215 "Anne and Caroline are actually going to come here soon because they work here, and you are going to give them their boxes. You can decide what they get, then you'll give the boxes to them, and it will be interesting to see what they think." 


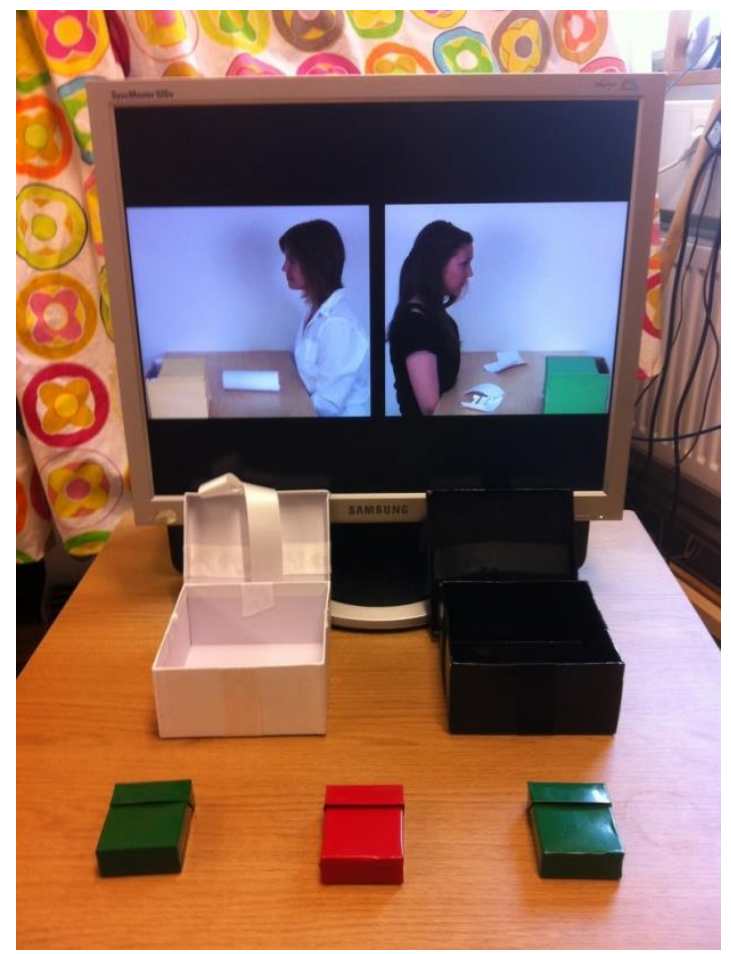

Fig. 1. The participants' view of the screen, boxes, and sweets, at the start of the distribution phase.

In both conditions the experimenter then took out the two packets of good sweets and the one packet of disgusting sweets, placed them in a row symmetrically in front of the two boxes with the disgusting sweets in the middle, and explained "You can give them the packets in their boxes, and you get to decide what they get. You decide if anyone should get the disgusting sweets and if anyone should get the good sweets. You don't need to give out all the packets. While you are doing that I'll get some work done." While distributing, the participant could see the onscreen final still tableau with the antisocial actor sitting by the 230 drawing she ripped up and the neutral actor by the drawing she left whole (Figure 1). The experimenter turned so she could not see the participant, and appeared to busy herself until the participant said they were finished, asking for such an indication if she could hear they were finished but had not said so. If she heard no activity after $10 \mathrm{~s}$ she reminded the participant "you can put into the boxes now". The rationale for providing two packets of good sweets but only one packet of bad sweets was so as not to push children into unwillingly allocating the bad sweets: this way, allocating one packets of good sweet to each actor was an obvious possible choice; and further, provision of two packets of bad sweets might have been interpreted as encouragement to allocate them to both actors.

In the justification phase, immediately after the packet distribution was

240 complete, if the participant had allocated the disgusting sweets, the experimenter asked the participant to explain "why they gave the red/green packet to Anne/Caroline", asking about each actor in counterbalanced order. Questions were not put if disgusting sweets were not allocated to avoid participants interpreting the question as an implication that disgusting sweets should have been allocated. Answers were scored from video by two independent 245 coders into two categories: containing or not containing reference to the actors' antisocial actions or character. The criterion for scoring was explicit description of the action (e.g. "because she tore up the drawing") or antisociality (e.g. "because she was mean"). Interobserver reliability was $100 \%$. 


\section{Results}

All participants gave at least one sweet packet (good or disgusting) to each actor. In the anonymous condition, more participants gave the disgusting sweets to the antisocial actor $(62 \%)$ than to the neutral actor (4\%, one participant), $p<.001$, sign test (Figure 2); 33\% did not allocate them. In the in-person condition, the proportion who gave the disgusting sweets to the antisocial actor $(21 \%)$ was not significantly different from the proportion giving them to the neutral actor ( $4 \%$, one participant), $p=.219$, sign test (Figure 2 ); $75 \%$ did not allocate them. The proportion of participants in the anonymous condition who gave the antisocial actor disgusting sweets was therefore greater than in the in-person condition, $p=.007$, Fisher's exact test, relative risk $=3.0$.

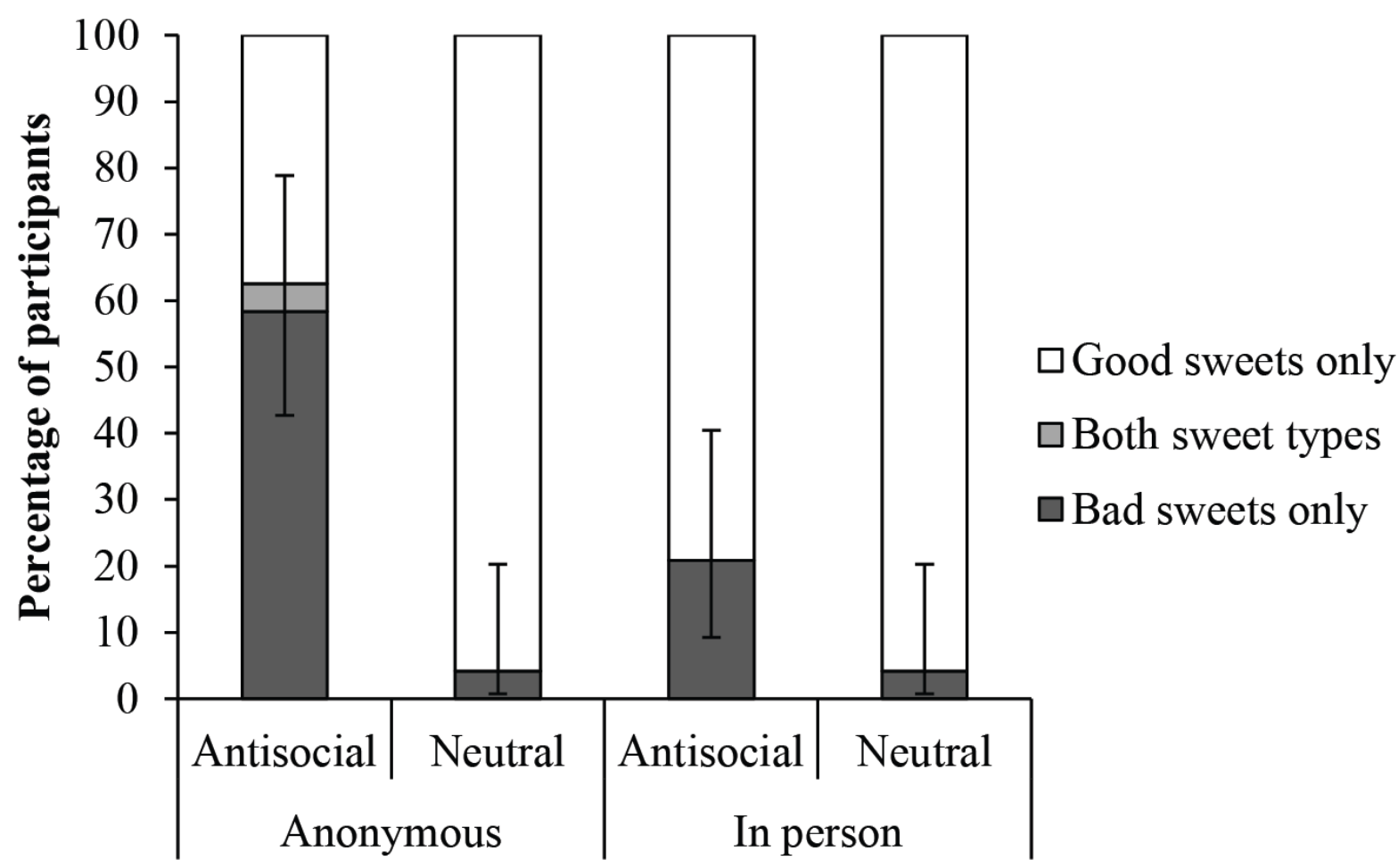

Fig. 2. Sweet allocation (good sweets or disgusting fake sweets) to antisocial and neutral recipients by five-year-olds. Participants are told the allocations will be anonymous $(n=24)$ or in person $(n=24)$. Error bars show $95 \%$ confidence intervals for the percent of children giving bad sweets.

In both conditions $96 \%$ of participants gave at least one packet of good sweets to the neutral actor. In the anonymous condition, fewer (42\%) gave good sweets to the antisocial than neutral actor, $p=.009$, Fisher's exact test, relative risk $=1.9$. In the in-person condition, however, there were not significantly fewer (79\%) giving good sweets to the antisocial than neutral actor, $p=.094$, Fisher's exact test, relative risk $=1.2$ (Figure 2).

In the anonymous condition, 9 of 11 boys ( $82 \%)$ gave the disgusting sweets to the antisocial actor, whereas 6 of 13 girls (46\%) did so, $p=.105$, Fisher's exact test, relative risk $=1.8$. However, when considering whether children gave only disgusting sweets to the antisocial actor (one girl gave both types of sweets to the antisocial actor), significantly more boys $(82 \%)$ than girls $(38 \%)$ did so, $p=.047$, Fisher's exact test, relative risk $=2.2$. 
In the anonymous condition $71 \%$ of participants who gave the disgusting sweets to the antisocial actor justified the allocation with reference to her antisocial actions or character. The equivalent proportion for the in-person condition was $40 \%$. The small number of in-person condition participants who allocated the disgusting sweets does not allow useful cross-condition comparisons or gender comparison in the in-person condition. In all but one case, those who allocated disgusting sweets to the antisocial actor without justifying with reference to her antisocial actions or character were either unwilling/unable to answer or gave circular justifications (e.g. "because I wanted to").

\section{Discussion}

Children allocating sweets anonymously usually chose to give the antisocial actor disgusting sweets. Because most children's justifications clearly indicated that they did so because of the actor's antisocial act, and because they did not allocate disgusting sweets to the neutral actor, this clearly demonstrates that five-year-olds are spontaneously motivated to punish real antisocial individuals. Furthermore, this represents third-party punishment, because participants were not directly affected by the antisocial act.

Because the participants did not actually meet the actors, although they were described as real and as really having performed the action, the argument that the participants experienced the punishment as real requires support. Participants showed a strongly reduced tendency to allocate disgusting sweets to the antisocial actor when not anonymous. This

295 confirmed the prediction made on the assumption that participants would be much less willing to risk the potential cost of in-person punishment, as long as they believed it was real. As there is no similarly plausible explanation for this result, it provides strong support for the conclusion that participants experienced the punishment they allocated as real. That fiveyear-olds should modify their behavior towards recipients depending on whether they are

300 anonymous to them reflects previous findings that five-year-olds are more generous when not anonymous (Engelmann, Herrmann, \& Tomasello, 2012; Leimgruber, Shaw, Santos, \& Olson, 2012). In a previous study using a more complex and purely resource-exchange based paradigm, five-year-olds did not engage in third-party punishment of selfish individuals, although six-year-olds did (Jordan et al., 2014). The current result suggests that the previous

305 lack of punishment by five-year-olds may have been due to the complexity of the task demands rather than a developmental difference in punitive sentiment.

One alternative interpretation of the current result, which is not in terms of third-party punishment, is that participants punished tearing up of the drawing simple because it appeared destructive, rather than because it was a transgression against a third party.

310 Although the current data cannot exclude this possibility, on the basis of previous data we regard it as unlikely. In a study of sympathy, from 18 months children distinguished between situations when an object was destroyed depending on whether or not it was a prized possession (Vaish et al., 2009). In another study, most six-year-olds showed concern when someone's drawing was torn up, but none did so when the torn paper belonged to no one

315 (Hobson, Harris, Garcia-Perez, \& Hobson, 2009).

The finding that five-year-olds punish in a situation in which they experience the punishment as really being inflicted is a notable advance because previous studies in which children this age or younger punished involved punishment that was hypothetical or inflicted on puppets. Although Smetana et al. (1993) asked children about real transgressions

320 they had actually observed, as in other interview studies they could only hypothetically advocate punishment. This difference is important because behavior individuals hypothetically advocate is often not the same as behavior they actually carry out 
(FeldmanHall et al., 2012; Smith et al., 2013), meaning that it was until now unclear if children this age actually engage in third-party punishment.

In the in-person condition, the $21 \%$ of participants who allocated disgusting sweets to the antisocial actor was greater, but not significantly so, than the $4 \%$ who allocated disgusting sweets to the neutral actor. This therefore represents weak support for costly thirdparty punishment in five-year-olds. This is hardly surprising, however, considering how a five-year-old is likely to feel about the potential consequences of giving in-person something unpleasant to a relatively unknown but antisocial adult. Future experiments to investigate costly third-party punishment in preschoolers could use a minor economic cost (as Jordan et al., 2014, did with six-year-olds) rather than a potentially severe social cost. Robbins and Rochat (2011) demonstrated that by five years and possibly earlier, children will pay a minor economic cost to punish a puppet that behaves unfairly, although their design cannot separate third-party from simpler second-party punishment.

Although studies of third-party punishment in young children are very rare, our results are in line with a range of studies demonstrating that preschoolers discriminate against moral norm violators in other ways. In addition to the previously mentioned interview studies, it has been demonstrated that two-, three- and four-year-olds are less likely to help 340 antisocial actors (Dahl et al., in press; Kenward \& Dahl, 2011; Vaish et al., 2010), and that three-year-olds verbally protest against an antisocial puppet's actions (Vaish et al., 2011). Furthermore, in one study preschoolers tattled against norm-violating members of their own peer-group, although almost always when they themselves were the victim (Ingram \& Bering, 2010). The authors argued that attention-seeking and the desire for inequities to be corrected

345 were more important factors than punishment-seeking for motivating such behavior. Although these previous studies demonstrated that children discriminate against antisocial individuals in various ways, this study further clearly demonstrates that preschoolers will take active steps to directly cause a negative outcome for a real actor who was antisocial to a third-party, i.e. engage in real third-party punishment.

Punishment is frequently advocated by adults because of an intrinsic belief that antisocial actions deserve punishment, i.e. a belief in the appropriateness of retribution (Carlsmith \& Darley, 2008; Keller et al., 2010). It is possible, however, that young children, rather than possessing an intrinsic desire to cause negative outcomes for antisocial individuals, punish because they have observed that adults sometimes punish and therefore

355 believe the behavior is expected of them. On the basis of other data, however, this latter possibility appears unlikely. Firstly, a survey of Swedish parents from a relevant range of demographic backgrounds indicated that they seldom punish their wrong-doing children, preferring to command, restrain, or reason (the most common punishment type, priviledge withdrawal, has a self reported prevelance of 6\%, Palmérus, 1999; see also Sorbring,

360 Rodholm-Funnemark, \& Palmérus, 2003). Swedish children are generally therefore not strongly socialized to punish.

Secondly, evidence from interview studies indicates that preschoolers' attitudes towards moral violations, including deservingness of punishment, are generally independent of authority judgments (Smetana, 1985, 2006; Tisak \& Turiel, 1988). Thirdly, it was previously found that following experimenters' demonstration of a puppet story in which a victim rather than perpetrator was punished, four-year-olds tended to correct the story when retelling it so that the perpetrator was punished (Kenward \& Östh, 2012). This indicated that preschoolers' punishment choices usually went contrary to the influence of an experimenter when the punishment appeared unfair. Together these studies strongly suggest that an 
370 intrinsic retributive desire for punishment is a stronger motivator of third-party punishment in preschoolers than a desire to conform to the expectations of adults.

Boys were more likely than girls to punish in the antisocial condition, although this result should not be regarded as highly robust because it held statistically only when excluding the ambiguous behavior of one individual who allocated both types of sweets to the antisocial individual. This result could indicate that boys judge transgressions more seriously, or that they are more willing to actually inflict punishment. The latter interpretation would be most appropriate, because previous studies have demonstrated a lack of gender differences in young children's moral judgments (Smetana, 2006; Walker, 2006), but clear gender differences in willingness to inflict physical harm (Card et al., 2008). We note that this result

380 suggests that participants did interpret allocation of disgusting sweets as directly causing harm, because while boys are known to be more willing to directly harm, they are if anything less likely to engage in more indirect forms of harm such relational aggression (Card et al., 2008). It is not yet possible to determine whether boys have a greater tendency specifically to punish, or whether the results reflects boys' more general and well-known greater tendency to 385 inflict physical harm.

We conclude by discussing the implications of the demonstration that a majority of five-year-olds in this sample possessed third-party punitive sentiment sufficient to motivate punishment of antisocial adults. This early development of strong punitive sentiment combined with the fact that adults from similar populations also possess similar

390 retribution-based sentiments (Carlsmith \& Darley, 2008; Keller et al., 2010) suggests that punitive sentiment is a deep-seated human motivation. This may help to explain why humans have sometimes created institutions of punishment which are arguably more efficient at causing harm to norm-violators than they are at reducing norm-violations (Cullen et al., 2011; Drucker, 2011; Garland, 2001; Rubin, 2004).

An important question is the source of the punitive sentiment. The prevalence of punishment within societies is an obvious potential socialization source, but it has also been suggested that there may be biologically evolved domain-specific mechanisms promoting third-party punishment. Consistent with this idea are the observations that children already in their second year prefer to inflict a negative outcome on an antisocial than on a neutral puppet and that 8-month-olds are attracted to puppets who hinder puppets who were themselves antisocial (Hamlin et al., 2011). The finding here of a strong punitive tendency despite the above-mentioned lack of strong socialization pressures in the typical Swedish preschooler's environment might be taken as tentative circumstantial support for this idea. However, although this work establishes that young children really want to engage in thirdparty punishment, more work is needed before the origins of the punitive sentiment can be firmly established.

\section{Acknowledgements}

Thanks to Alex A. S. Weir for the original idea of using disgusting sweets as punishment. This work was supported by Riksbankens Jubileumsfond (Bank of Sweden 410 Tercentenary Fund) Grant P2008-01039:1.

\section{References}

Aquino, K., Tripp, T. M., \& Bies, R. J. (2001). How employees respond to personal offense: The effects of blame attribution, victim status, and offender status on revenge and reconciliation in the workplace. Journal of Applied Psychology, 86, 52-59. doi: 10.1037/0021-9010.86.1.52

Baron, R. A., \& Richardson, D. R. (Eds.). (1994). Human aggression. New York: Plenum. 
Boyd, R., \& Richerson, P. (1992). Punishment allows the evolution of cooperation (or anything else) in sizable groups. Ethology and Sociobiology, 13, 171-195.

Card, N. A., Stucky, B. D., Sawalani, G. M., \& Little, T. D. (2008). Direct and indirect aggression during childhood and adolescence: a meta-analytic review of gender differences, intercorrelations, and relations to maladjustment. Child Development, 79, 1185-1229. doi: 10.1111/j.1467-8624.2008.01184.x

Carlsmith, K. M., \& Darley, J. M. (2008). Psychological aspects of retributive justice. Advances in Experimental Social Psychology, 40, 193-236. doi: 10.1016/s00652601(07)00004-4

Cullen, F. T., Jonson, C. L., \& Nagin, D. S. (2011). Prisons do not reduce recidivism: The high cost of ignoring science. The Prison Journal, 91, 48S-65S. doi: $10.1177 / 0032885511415224$

Dahl, A., Schuck, R. K., \& Campos, J. J. (in press). Do young toddlers act on their social preferences? Developmental Psychology. doi: 10.1037/a0031460

de Quervain, D. J. F., Fischbacher, U., Treyer, V., Schelthammer, M., Schnyder, U., Buck, A., \& Fehr, E. (2004). The neural basis of altruistic punishment. Science, 305, 12541258.

Drucker, E. (2011). A plague of prisons: The epidemiology of mass incarceration in America New York: New Press.

Engelmann, J. M., Herrmann, E., \& Tomasello, M. (2012). Five-year olds, but not chimpanzees, attempt to manage their reputations. Plos One, 7, e48433. doi: 10.1371/journal.pone.0048433

Fehr, E., \& Fischbacher, U. (2003). The nature of human altruism. Nature, 425, 785-791.

440 Fehr, E., \& Gächter, S. (2002). Altruistic punishment in humans. Nature, 415, 137-140.

FeldmanHall, O., Mobbs, D., Evans, D., Hiscox, L., Navrady, L., \& Dalgleish, T. (2012). What we say and what we do: The relationship between real and hypothetical moral choices. Cognition, 123, 434-441. doi: 10.1016/j.cognition.2012.02.001

Garland, D. (Ed.). (2001). Mass imprisonment: Social causes and consequences New York: Sage.

Gintis, H., Henrich, J., Bowles, S., Boyd, R., \& Fehr, E. (2008). Strong reciprocity and the roots of human morality. Social Justice Research, 21, 241-253.

Hamlin, J. K., Wynn, K., Bloom, P., \& Mahajan, N. (2011). How infants and toddlers react to antisocial others. Proceedings of the National Academy of Sciences of the United

$450 \quad$ States of America, 108, 19931-19936. doi: 10.1073/pnas.1110306108

Henrich, J., McElreath, R., Barr, A., Ensminger, J., Barrett, C., Bolyanatz, A., . . Ziker, J. (2006). Costly punishment across human societies. Science, 312, 1767-1770. doi: $10.1126 /$ science. 1127333

Hobson, J. A., Harris, R., Garcia-Perez, R., \& Hobson, R. P. (2009). Anticipatory concern: a study in autism. Developmental Science, 12, 249-263.

Ingram, G. P. D., \& Bering, J. M. (2010). Children's tattling: The reporting of everyday norm violations in preschool settings. Child Development, 81, 945-957.

Janssen, M. A., \& Bushman, C. (2008). Evolution of cooperation and altruistic punishment when retaliation is possible. Journal of Theoretical Biology, 254, 541-545. doi:

$460 \quad 10.1016 /$ j.jtbi.2008.06.017

Jensen, K. (2010). Punishment and spite, the dark side of cooperation. Philosophical Transactions of the Royal Society B-Biological Sciences, 365, 2635-2650. doi: 10.1098/rstb.2010.0146

Jordan, J. J., McAuliffe, K., \& Warneken, F. (2014). Development of in-group favoritism in children's third-party punishment of selfishness. Proceedings of the National Academy of Sciences, 111, 12710-12715. doi: 10.1073/pnas.1402280111 
Keller, L. B., Oswald, M. E., Stucki, I., \& Gollwitzer, M. (2010). A closer look at an eye for an eye: Laypersons' punishment decisions are primarily driven by retributive motives. Social Justice Research, 23, 99-116. doi: 10.1007/s11211-010-0113-4

Kenward, B., \& Dahl, M. (2011). Preschoolers distribute scarce resources according to the moral valence of recipients' previous actions. Developmental Psychology, 47, 10541064. doi: $10.1037 / \mathrm{a} 0023869$

Kenward, B., \& Östh, T. (2012). Enactment of third-party punishment by four-year-olds. Frontiers in Psychology, 3. doi: 10.3389/fpsyg.2012.00373

Leimgruber, K. L., Shaw, A., Santos, L. R., \& Olson, K. R. (2012). Young children are more generous when others are aware of their actions. Plos One, 7, e48292. doi: 10.1371/journal.pone.0048292

Lergetporer, P., Angerer, S., Glätzle-Rützler, D., \& Sutter, M. (2014). Third-party punishment increases cooperation in children through (misaligned) expectations and conditional cooperation. Proceedings of the National Academy of Sciences, 111, 6916-6921. doi: 10.1073/pnas.1320451111

Mathew, S., \& Boyd, R. (2011). Punishment sustains large-scale cooperation in prestate warfare. Proceedings of the National Academy of Sciences. doi: 10.1073/pnas.1105604108

485 Melis, A. P., \& Semmann, D. (2010). How is human cooperation different? Philosophical Transactions of the Royal Society B: Biological Sciences, 365, 2663-2674. doi: 10.1098/rstb.2010.0157

Nowak, M. A., \& Sigmund, K. (2005). Evolution of indirect reciprocity. Nature, 437, 12911298.

490 Palmérus, K. (1999). Self-reported discipline among Swedish parents of preschool children. Infant and Child Development, 8, 155-171.

Pew Center. (2008). One in 100: Behind bars in America 2008. Retrieved 26th September, 2013, from http://www.pewcenteronthestates.org/uploadedFiles/8015PCTS_Prison08_FINAL_21-1_FORWEB.pdf

Price, M. E., Cosmides, L., \& Tooby, J. (2002). Punitive sentiment as an anti-free rider psychological device. Evolution and Human Behavior, 23, 203-231.

Raihani, N. J., Thornton, A., \& Bshary, R. (2012). Punishment and cooperation in nature. Trends in Ecology \& Evolution, 27, 288-295. doi: 10.1016/j.tree.2011.12.004

Riedl, K., Jensen, K., Call, J., \& Tomasello, M. (2011). Restorative justice and third party punishment in preschool children. Paper presented at the SRCD Biennial Meeting, Vancouver.

Riedl, K., Jensen, K., Call, J., \& Tomasello, M. (2012). No third-party punishment in chimpanzees. Proceedings of the National Academy of Sciences, 109, 14824-14829. doi: 10.1073/pnas.1203179109

Robbins, E., \& Rochat, P. (2011). Emerging signs of strong reciprocity in human ontogeny. Frontiers in Psychology, 2. doi: 10.3389/fpsyg.2011.00353

Robinson, P. H., Kurzban, R., \& Jones, O. D. (2007). The origins of shared intuitions of justice. Vanderbilt Law Review, 60, 1633-1687.

510 Rubin, E. (2004). Just say no to retribution. Buffalo Criminal Law Review, 7, 17-83.

Singer, T., Seymour, B., O'Doherty, J. P., Stephan, K. E., Dolan, R. J., \& Frith, C. D. (2006). Empathic neural responses are modulated by the perceived fairness of others. Nature, 439, 466-469.

Smetana, J. G. (1981). Preschool children's conceptions of moral and social rules. Child Development, 52, 1333-1336. 
Smetana, J. G. (1985). Preschool childrens conceptions of transgressions: effects of varying moral and conventional domain-related attributes. Developmental Psychology, 21, 1829. doi: 10.1037/0012-1649.21.1.18

Smetana, J. G. (2006). Social-cognitive domain theory: Consistencies and variations in children's moral and social judgments. In M. Killen \& J. G. Smetana (Eds.), Handbook of moral development (pp. 119-153). Mahwah, NJ: Lawrence Erlbaum.

Smetana, J. G., Schlagman, N., \& Adams, P. W. (1993). Preschool children's judgments about hypothetical and actual transgressions. Child Development, 64, 202-214.

Smith, C. E., Blake, P. R., \& Harris, P. L. (2013). I Should but I Won't: Why Young Children Endorse Norms of Fair Sharing but Do Not Follow Them. Plos One, 8, e59510. doi: 10.1371/journal.pone.0059510

Sorbring, E., Rodholm-Funnemark, M., \& Palmérus, K. (2003). Boys' and girls' perceptions of parental discipline in transgression situations. Infant and Child Development, 12, 53-69.

530 Stern, B. L., \& Peterson, L. (1999). Linking wrongdoing and consequence: A developmental analysis of children's punishment orientation. Journal of Genetic Psychology, 160, 205-224.

The Economist. (2010). Rough Justice in America. The Economist, 396, 21-24.

Tisak, M. S., \& Turiel, E. (1988). Variation in seriousness of transgressions and childrens moral and conventional concepts. Developmental Psychology, 24, 352-357. doi: $10.1037 / / 0012-1649.24 .3 .352$

Vaish, A., Carpenter, M., \& Tomasello, M. (2009). Sympathy through affective perspective taking and its relation to prosocial behavior in toddlers. Developmental Psychology, 45, 534-543.

540 Vaish, A., Carpenter, M., \& Tomasello, M. (2010). Young children selectively avoid helping people with harmful intentions. Child Development, 81, 1661-1669. doi: 10.1111/j.1467-8624.2010.01500.x

Vaish, A., Missana, M., \& Tomasello, M. (2011). Three-year-old children intervene in thirdparty moral transgressions. British Journal of Developmental Psychology, 29, 124130. doi: 10.1348/026151010x532888

Walker-Andrews, A. S., \& Kahana-Kalman, R. (1999). The understanding of pretence across the second year of life. British Journal of Developmental Psychology, 17, 523-536. doi: 10.1348/026151099165456

Walker, L. J. (2006). Gender and morality. In M. Killen \& J. G. Smetana (Eds.), Handbook of moral development (pp. 93-115). Mahwah, NJ: Lawrence Erlbaum. 